\title{
A Study on the Roles of Designers Co-Evolving with Tools
}

LIM Jeong-Sub and JUNG Eui-Chul ${ }^{*}$

Seoul National University

* Corresponding author email: jech@snu.ac.kr

doi: $10.21606 /$ dma.2018.533

\begin{abstract}
Humans have always been making tools, creating artefacts with the tools and also using those artefacts as tools. The concept of tools is changing from the expansion of the human body to the expansion of human intelligence. The development of computer technology and the emergence of artificial intelligence raise serious questions about the faculties and roles of humans. The same is true for the faculties and roles of designers who use computers as their main tool in their work. In this paper, the inherent faculties of the human mind, revealed through the Kantian approach, are applied to designers. According to this, it is explained how designers use their own faculties in the world of human artefacts. The co-evolutionary relationship between computers, as evolving tools, and designers is analysed by establishing roles in mutual relations at each phase. The evolution of tools requires designers to take on new roles, which helps designers to better use their faculties.
\end{abstract}

tools of design; artificial intelligence; role of designer; generative design

\section{Introduction}

Henri Bergson (1998) defined intelligence as "the faculty of manufacturing artificial objects, especially tools to make tools, and of indefinitely varying the manufacture" (p. 139). The term Homo Faber, Latin for 'the man who make things', symbolically represents a human view that intelligence is expressed by the tendency of humans to make and use tools to control their own fate and their environment. Since the beginning of human history, humans have always been making tools, creating artefacts with the tools and also using those artefacts as tools. Martin Heidegger (1996) said, "Production itself is always a using of something for something" (p. 66). It is usually said that everything but nature is made by humans. According to this saying, human beings live every moment in relation to tools. Every time humans make artefacts, they use tools, so the way humans relate to artefacts is heavily influenced by tools. As time goes by and as technology develops, tools evolve, which also interactively impacts human roles. Even if the same artefacts are made, the role of humans continues to change as the tools evolve. If we just look at the periods before and after the appearance of computers, the role of humans in making artefacts is very different. In other words, humans and tools co-evolve. 
In general, on the other hand, the role of an individual is determined by his or her abilities, regardless of the gender, race or other innate aspects of the person. When discussing human ability, the function of the human brain is often mentioned. According to this, human ability can be roughly divided into two sections in terms of the parts of the human brain, which are called the 'creative part' and the 'repetitive part'. It is said that the right hemisphere of the human brain is related to creative, intuitive, synthesising and subjective thought, while the left hemisphere is associated with logical, rational, analytical and objective thought. According to this theory, human beings have always been using these two capabilities at the same time or alternately. The thinkers in the early history of computer science who were optimistic about the future of humans with computers anticipated that computers would make the repetitive part of the human brain obsolete. Thus, the ability to think creatively is inherent in humans, and with the advent of computers, humans could become even more creative. Tools not only can help human beings, but they also make it possible for humans to make better use of their abilities.

Designers have traditionally used drafting tools, such as drafting boards, compasses, triangles, Tsquares, scales, templates, French curves, erasers, and so on. There are many other tools, but pencil and paper are the main tools used by designers. Since the advent of computers, however, most of the functions of drafting tools have been incorporated into computers. Computers are one of the most important tools for designers, and they are still evolving. The emergence of computers led to a new paradigm of the relationship between designers and tools. There are a large number of studies on the abilities and roles of designers using computers as tools, and there are some that worry about the negative impact of computers. These topics are still valid, and they will become more important in the future because of the development of artificial intelligence technology. Jeff Kowalski, a CTO of Autodesk, has redefined CAD as the abbreviation for 'Computer as Designer'. The typical example is Generative Design, the new way of finding solutions in design by applying artificial intelligence technology. The Google Brain Team is also taking on new and challenging creative areas, letting machines with artificial intelligence compose music or draw pictures. The other part of the human brain, the creative part, seems to be being replaced by machines. The concept of tools has changed from the expansion of the human body to the expansion of human intelligence due to the development of computers. In the era of artificial intelligence, the tool is regarded as a personality.

As artificial intelligence is expected to emerge as a new paradigm of tools for designers, it is believed that designers' capabilities and roles need to be discussed at a more fundamental level than they were before. In this paper, firstly, by applying the Kantian approach to the faculties of humans, humans' inherent faculties from a philosophical viewpoint and designers' faculties as human beings will be examined. Secondly, on the basis of this, the roles of designers will be considered in the relationship between designers as humans and computers as tools. Finally, the way in which the roles of designers have continued to fluctuate in each phase of the evolution of computing tools will be analysed.

\section{The analysis of the faculties of designers}

Strictly speaking, there 'is' no such thing as a useful thing. There always belongs to the being of a useful thing a totality of useful things in which this useful thing can be what it is. A useful thing is essentially 'something in order to...'. The different kinds of 'in order to' such as serviceability, helpfulness, usability, handiness, constitute a totality of useful things. (Heidegger, 1996, p. 64)

From the use of classical drafting tools to the days of artificial intelligence, the boundary between designers and tools has become increasingly blurred. This is not only due to the changes in the interface between designers and tools as computer technology advances. This is also because artificial intelligence technology has emerged and computers as tools have been trying to replace human intelligence. The history of artificial intelligence research has two main paradigms: computationalism (or symbolism) and connectionism. While computationalists view the human 
mind as a computable symbol processing system, connectionists believe the human mind can be explained by artificial neural networks. According to both paradigms, ultimately, human intelligence will be totally replaced by machines. It has been considered impossible until now, but it cannot be taken lightly. Regardless of one's stance on the issue, it must be admitted that artificial intelligence is changing real life now.

In particular, the use of artificial intelligence in the field of design has been accelerated in recent years. Adobe's Project Scribbler uses the deep learning-based image generation system to automatically colorize black-and-white photos or sketches. Google's AutoDraw uses machine learning algorithms to analyse user's doodles, find out what the user is trying to draw, and suggest a matching picture from the database. Design platforms that use artificial intelligence, such as Logojoy, analyse the mathematical patterns of visual elements in logos or business cards to produce results tailored to the user's preferences. On the other hand, in industrial design, artificial intelligence software, such as Autodesk Dreamcatcher, allows computers to generate their own chair designs. Even if user do not have a professional design education, the software will suggest various design alternatives to the user by entering the basic geometric elements of the chair, the loads applied to it, and the materials to be used in the manufacturing. When we look at the examples listed above, it is no longer awkward to say that 'the machine designs'.

"Asking 'Can a machine design?' is similar to asking 'Can a machine think?'” (Cross, 2001b, p. 44). In the history of Western philosophy, almost every philosopher has sought to distinguish humans from animals, in that humans have intellect, albeit for different reasons. Thus, humans have a different status from animals on an ontological basis. The dominant reason that humans are considered ontologically superior to animals is that humans can think. On the other hand, in terms of tools that are intelligent, like evolving computers, it can be said that the present tools have changed their ontological position from the traditional tools. When we do some intelligent work, we say that we 'use' computers, even though we get practical help from the computers in the middle of the operations. If the machines with intelligence ultimately seek to replace human intelligence, this means that the tools try to move their ontological status from the normal tool level to the nearhuman level.

As can be seen in Figure 1, in the relationship between designers and artefacts over time, the ontological status of tools becomes increasingly clear, and it can be explained as being closer to the designers as humans. The word 'use' is still valid, but in the future, can humans say they 'use' artificial intelligence? In order for artificial intelligence to be considered as a tool, it is necessary to review the faculties of humans at a fundamental level.

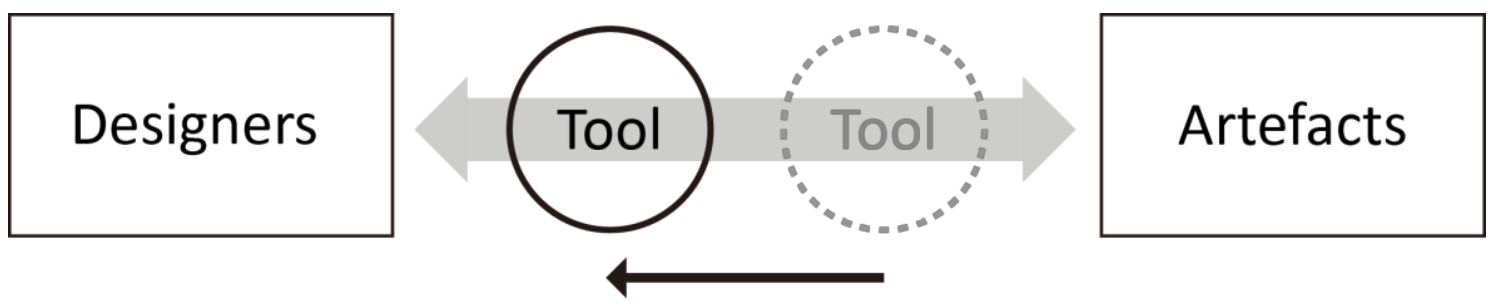

Figure 1 The changes in the ontological status of tools over time

\subsection{The Kantian approach to the faculties of humans}

Humans make artefacts when they want to seek or achieve something. Designers also make artefacts when they want to solve problems. At this point, designers may ask, 'What do I design?' and this question itself shows that they are designers. Philosophers, on a deeper level, ask, 'What do I pursue?' A question reflects the nature of the being asking the question, and in order to explore the faculties of the being, the following question may be asked: 'How can it be possible?' Since the time of the ancient Greeks, philosophers have explored the transcendental values pursued by humans and tried to explain human existence through the faculties of the human mind to make it 
possible. Those explanations, however, were generally focused on nature, the universe and God. In other words, it has been explained that by the providence of nature or the universe, or by the power of God, human beings can have such faculties to pursue the transcendental values and to ask questions.

On the other hand, representative philosopher of the Enlightenment, also regarded as a pioneer of modern philosophy, Immanuel Kant tried to explain the existence of human beings by focusing on humans themselves. He emphasised the active and voluntary faculties of human beings as a recognition subject.
Ancient philosophers were quite mistaken in the role they assigned man in the world, since they considered him a machine within it, entirely dependent on the world or on external things and circumstances, and so made him an all but passive part of the world. Now the critique of reason has appeared and assigned man a thoroughly active existence in the world. Man himself is the original maker of all his representations and concepts, and ought to be the sole author of all his actions. (Kant, 1979, p. 127-129)

Kant's philosophy is often called critical philosophy, where the word 'critique' is asking for possible grounds (i.e., 'how can it be possible?'). Kant has formulated three values that humans should desire and pursue: truth, goodness and beauty. These are the transcendental values that have been valid until now. According to Kant, the questions asked by humans using their faculties of the mind are summarised in the following three.

- What can I know?

- What should I do?

- What may I hope?

Kant himself tried to answer each of these questions through the following books: Critique of Pure Reason, Critique of Practical Reason and Critique of Judgment. The unique faculties of the human mind revealed in the process of asking these questions are as follows: 'cognitive faculties', 'faculty of desire', and 'feeling of pleasure and displeasure'. Using these faculties, humans can ask the three questions above and thus pursue transcendental values. Ultimately, these three questions are related to the question 'What is the human being?'. Table 1 shows Kant himself summarising the faculties of the human mind in the introduction of Critique of judgment.

Table 1 All the Faculties of the Mind (Kant, 2007, p. 32)

\begin{tabular}{llll}
\hline All the Faculties of the Mind & Cognitive Faculties & A priori Principles & Application \\
\hline Cognitive faculties & Understanding & Conformity to law & Nature \\
Feeling of pleasure and displeasure & Judgement & Purposiveness & Art \\
Faculty of desire & Reason & Final end & Freedom \\
\hline
\end{tabular}

On the other hand, just as the world of philosophical inquiry is the world of the human mind, the world of designerly inquiry is the world of human artefacts.

What designers know about especially is the 'artificial world' - the human-made world of artefacts. What they know how to do especially is the proposing of additions to and changes to the artificial world. Their knowledge, skills and values lie especially in the techniques of the artificial. (Cross, 2001a, p. 54)

Since Plato divided the world into the world of ideal forms and the perceptible world, the philosophers throughout history have mainly grasped the world as a dualistic world, a conceptual world and a practical world. In this context, thus, the world can be divided into two. These are the world of the human mind as a kind of conceptual world and the world of human artefacts as a kind of practical world. The world of human artefacts cannot be said to be a sub-world completely contained in the world of the human mind as a philosopher's inquiry object, because designers deal 
with artefacts outside of the human mind. It is, however, also not a world that is completely different from the world of the human mind, because artefacts are the things that are made by humans, and they are still connected with the human mind. Figure 2 is a schematic of the two worlds.

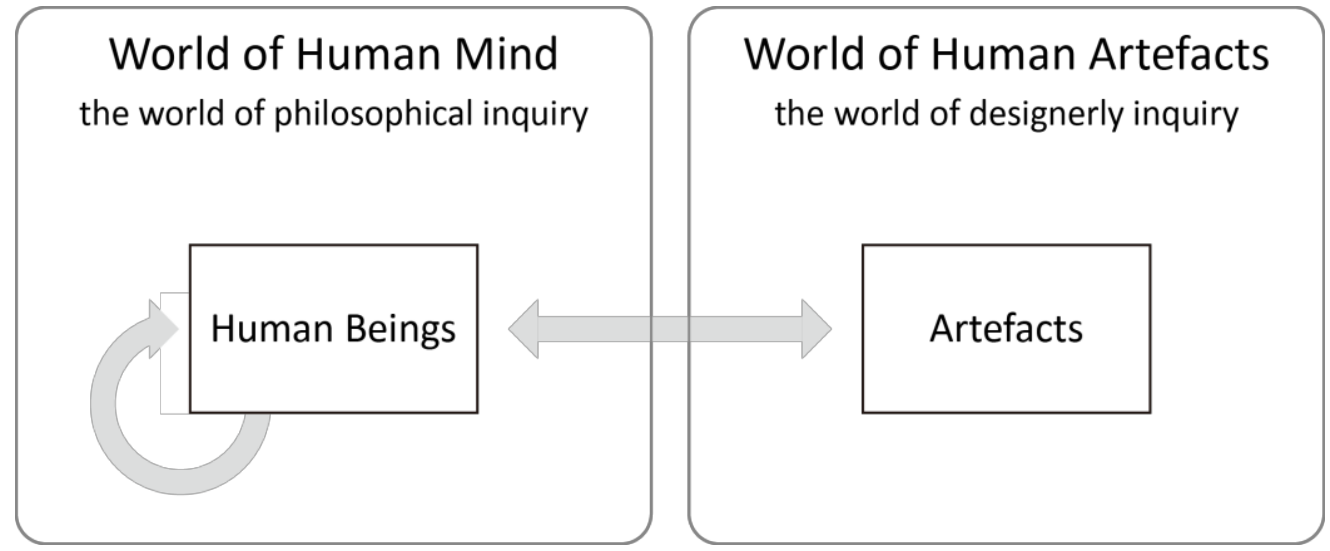

Figure 2 The world of the human mind and the world of human artefacts

\subsection{The faculties of designers as human beings}

In an experimental research study, Lawson (1984) compared the ways in which designers (in this case architects) and scientists solved the same problem. The scientists tended to use a strategy of systematically trying to understand the problem, in order to look for underlying rules which would enable them to generate an optimum solution. In contrast, the designers tended to make initial explorations and then suggest a variety of possible solutions until they found one that was good, or at least satisfactory. The evidence from the experiments suggested that scientists problem-solve by analysis, whereas designers problem-solve by synthesis; scientists use 'problem-focused strategies' and designers use 'solution-focused strategies'. (Cross, 2008, p. 21)

Designers are the people who solve problems. Designers use 'solution-focused strategies' in order to present a variety of possible solutions. The main task of designers is to make these solutions into artefacts in the real world. When designers think about an ideal solution, they, as human beings, can ask the following questions to the world of human artefacts using the faculties of the human mind.

- What could it be?

- What should it be?

- What might it be?

As for the first question, just as human beings can ask 'What can I know?' by using their cognitive faculties and pursue the truth, designers can also ask 'What could it be?' At this time, designers think about what artefacts can be realised with respect to the design problem. As for the second question, just as human beings can ask 'What should I do?' by using the faculty of desire and pursue goodness, designers can also ask 'What should it be?' At this time, designers take some actions in order to achieve the objective in the process of designing the artefacts. As for the third question, just as human beings can ask 'What may I hope?' by using the feeling of pleasure and displeasure and pursue beauty, designers can also ask 'What might it be?' At this time, designers consider what kind of artefacts they design will universally deliver satisfaction to humans. As a result, designers can ultimately ask 'What is the artefact?' Figure 3 is a diagram of the possible questions for each of the two worlds through the faculties of the human mind. 


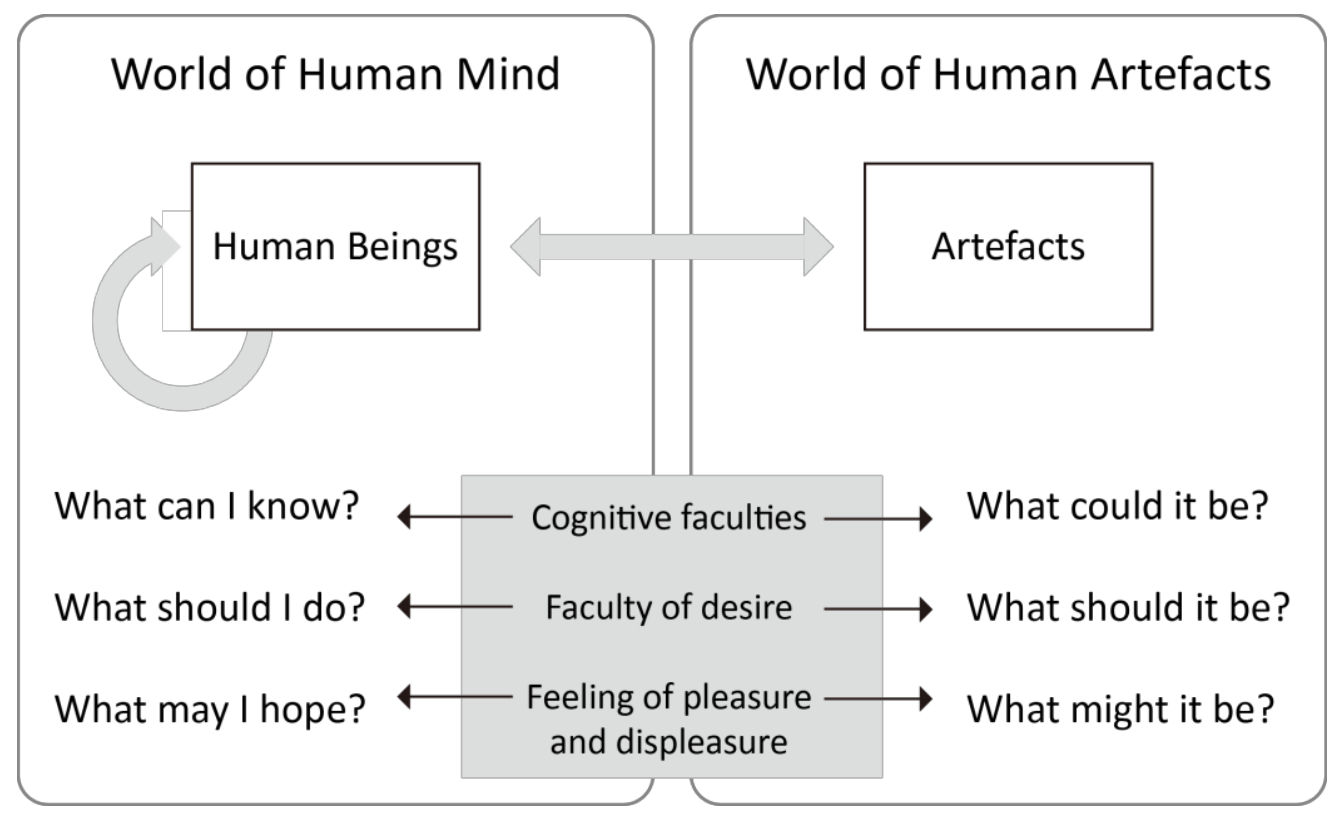

Figure 3 The possible questions for each of the two worlds through the faculties of the human mind

These three questions of designers are made possible by the unique faculties of the human mind. Through each of the faculties, we will look at how designers ask these questions.

\subsubsection{On the cognitive faculties}

Kant (2006) said, "Before the artist can present a physical form, he must have produced it in his power of imagination" (p. 67). Imagination, in this sentence, is the productive faculty of intuition that works without the presence of the thing. According to the common explanation of Critique of Pure Reason, human perception does not involve passively sensing the objects of the external world but reconstructing the objects actively from the inside of the mind through empirical data. When designers ask, 'What could it be?', they remind themselves of the final solution from within, through a variety of materials on design problems. At this point, it can be said that designers use their cognitive faculties.

\subsubsection{On the faculty of desire}

Kant (2006) defined desire as "the self-determination of a subject's power through the representation of something in the future as an effect of this representation" (p. 149). In another part, Kant (1998) also said, "The will is thought as a capacity to determine itself to acting in conformity with the representation of certain laws" (p. 36). The faculty of desire, or will, as a result, appears in the form of oughtness. In the world of the human mind, humans, as rational beings, can ask the question 'What should I do?' through self-legislation. In the world of human artefacts, designers also can ask the question 'What should it be?' through the faculty of desire.

\subsubsection{On the feeling of pleasure and displeasure (especially on sensuous pleasure)}

According to Kant (2006), "Enjoyment is a pleasure through sense, and what amuses sense is called agreeable" (p. 125). Furthermore, humans have a taste, as a formal sense, that "concerns the communication of our feeling of pleasure or displeasure to others" (p. 141). In addition, the satisfaction is produced by taste. "Now satisfaction that can be considered valid not merely for the subject who feels it but also for everybody else, that is, universally valid, must contain necessity" ( $p$. 141). When designers are asking 'What might it be?', designers are making artefacts not only for their own satisfaction but also aiming to universal for everyone. Taste "is the faculty of the aesthetic power of judgment to choose with universal validity" (p. 137). In here, taste is considered as a faculty of making social judgments. 
When designers ask these questions by using the faculties of the human mind, there can be no strict distinction between them. Designers are always asking these questions at every stage of the design process. For example, a designer who wants to design a chair might ask himself 'What is the chair itself?' or 'What could the chair be?' He may recall many forms in him, and sometimes, he might try creating some sketches with pencil and paper. He also might ask himself 'What is the purpose of the chair?' or 'What should the chair be?' He might think of its structure, material, combination and so on based on the purpose of the chair, and sometimes, he might create prototypes using the things around him. He also might ask himself 'What is the universally valid chair?' or 'What might the chair be?' He may think about the various people who will sit on the chair, the space where the chair will be placed, the mood of the chair and so on. These questions can sometimes be asked at the same time. All of these questions are constantly interacting with each other. As a result, designers, like humans themselves, use the inherent faculties of the human mind simultaneously and in combination. The questions that designers who explore the world of human artefacts can ask, and the faculties of designers to ask such questions, are summarised in Figure 4 below.

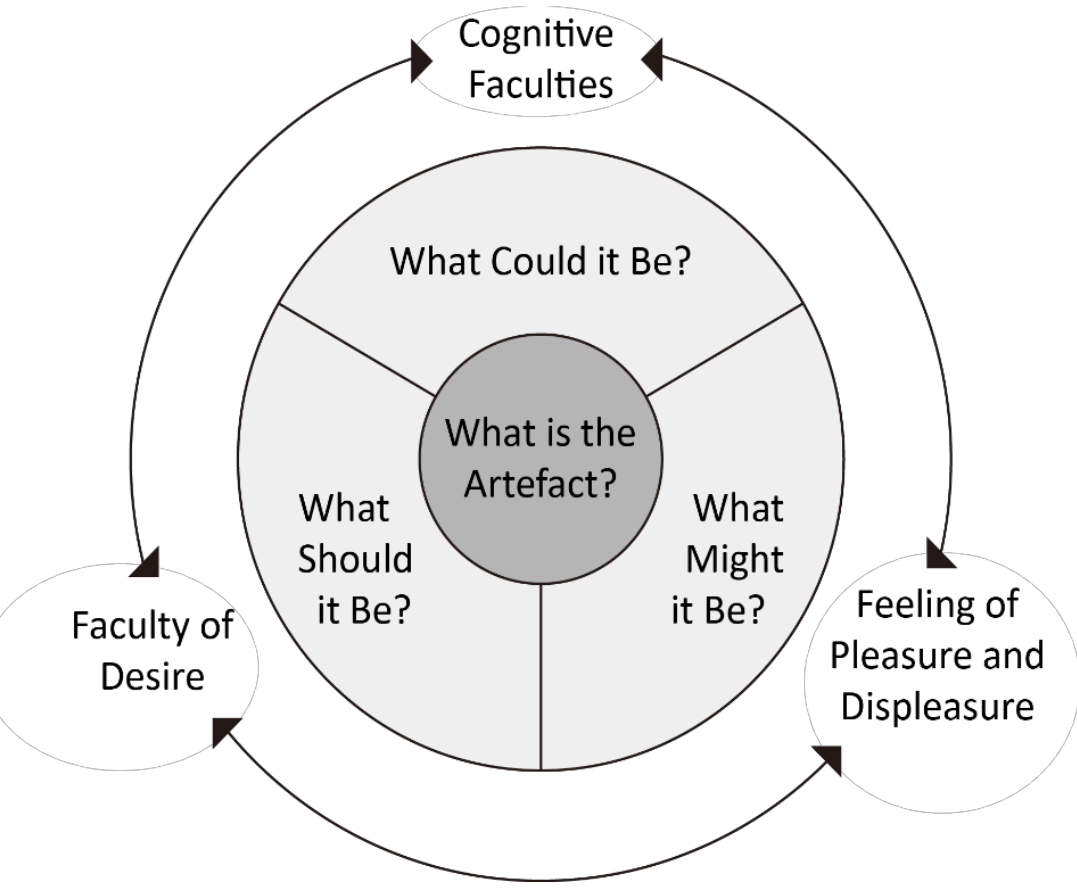

Figure 4 The relationship between faculties of designers and the questions available through the faculties.

\section{The analysis of the roles of designers}

In its familiarity with significance, Dasein is the ontic condition of the possibility of the disclosure of beings encountered in the mode of being of relevance (handiness) in a world that can thus make themselves known in their in-itself. As such, Dasein always means that a context of things at hand is already essentially discovered with its being. In that it is, Dasein has always already referred itself to an encounter with a 'world'. This dependency of being referred belongs essentially to its being. (Heidegger, 1996, p. 81)

Dasein (Heidegger's term, which means 'human being presences') exists in the world through making relationships with other beings. Heidegger calls these other beings 'beings in the world', and the things used by human beings, the tools, are called 'useful things'. Like shoes when they are worn, and like clocks when they tell the time, the tools have their own meaning of existence the moment when they are used. Heidegger (1996) said, "The kind of being of these beings is 'handiness'" (p. 67), and the word 'handiness' can be replaced by the phrase 'ready to hand'. Designers, on the other hand, use their faculties by questioning the world of human artefacts through the inherent faculties of the human mind. The roles of designers are affected by the tools 
they use in the world of human artefacts. While designers are using tools, their roles are determined in relation to the tools. Thus, in the world of the human mind, designers, as human beings, give the meaning of existence to the tools, whereas in the world of human artefacts, the tools influence the role of designers.

In the context of the relationship between designers as humans and computers as tools, there were generally optimistic prospects for the future of humankind with computers. Bush (1945) divided human thought into two types and said, "Creative thought and essentially repetitive thought are very different things". In the latter case, he predicted humans could get the help of the machines, the computers. This requires creative thought to select the appropriate data in the process and put it in the right place. However, the rest of the repetitive part is left to the computers. Licklider (1960) defined the roles of humans in the future symbiotic relationship between humans and computers as follows: Humans will "set the goals, formulate the hypotheses, determine the criteria and perform the evaluations" (p. 4). and the computers will perform the repetitive tasks that assist humans. He said, "Computing machines can do readily, well, and rapidly many things that are difficult or impossible for man" (p. 6), while "Men can do readily and well, though not rapidly, many things that are difficult or impossible for computers" (p. 6). In this context, Engelbart (1962) defined the future symbiotic relationship as the relationship between a 'human problem-solver' and a 'computer-clerk'.

On the other side, it can be said that the development of computer technology in the field of design has made the roles of computers evolve, and the new roles of designers in each phase have been required accordingly. Moreover, we cannot be certain that the opinions of the thinkers in the early history of computer science are still valid for computers in the era of artificial intelligence. Since the advent of computers, the history of CAD can largely be divided into three phases by the roles of computers as tools: computer-aided geometric design, algorithm-aided parametric design and artificial intelligence-aided generative design. Computer advances have come from geometrically aiding the visualisation of designers' ideas, computing optimised designs through algorithms and even suggesting many designs to designers through artificial intelligence technology. In this part, the roles of designers in the evolution phases of the roles of computers as tools will be examined.

\subsubsection{Before the appearance of computers}

Before computers appeared, or before the 1950s when computers began to be used in the field of design, designers performed all their design works with their hands and drafting tools alone. These tasks required very sophisticated skills and knowledge of a variety of geometrical concepts. The tools were made in shapes that fit their functions, and the designers used them for their own purposes. In this period during which tools were still seen as an extension of the human body, tools provided a kind of convenience to designers, but they were barely related to the designers' faculties of the mind. Therefore, these tools could only show the role of designers symbolically, but they were considered to have little effect on the role of designers. In this relationship between designers and tools, tools are tools, and designers are tool users.

\subsubsection{The first phase: computer-aided geometric design}

"CAD systems were originally intended to serve as a platform on which to develop designs graphically" (Vidal \& Mulet, 2006, p. 101). From Ivan Sutherland's Sketchpad, which can be called the beginning of CAD, to Adobe Illustrator, to Autodesk AutoCAD, CAD has generally been regarded as an important tool used to support designers. The most important role of CAD, in this phase, is to successfully visualise the image inside the designers. In pre-computer design works, it took a lot of time and effort for designers to fully visualise their ideas through pencil and paper and other drafting tools. CAD reduces the gap between the designers' internal image and the visualised image through the same task, with less time and effort. At this point, designers use their cognitive faculties as one of their faculties of the mind. Designers create forms, and computers support them in visualising them. This means that computers have begun to replace the repetitive part of the human ability in earnest as a calculator (i.e. its essential role). When Konstantin Grcic designed Chair_ONE, it was one of the first times that he used three-dimensional computer modelling to design. Grcic 
(2015) said, "Computers are an extremely important tool for assembling three-dimensional shapes and coming up with the parts for the model". Computers help designers make better use of their cognitive faculties to create forms. Therefore, as can be seen in Figure 5, the role of designers as creators and the role of computers as supporters can be defined in relation to each other.

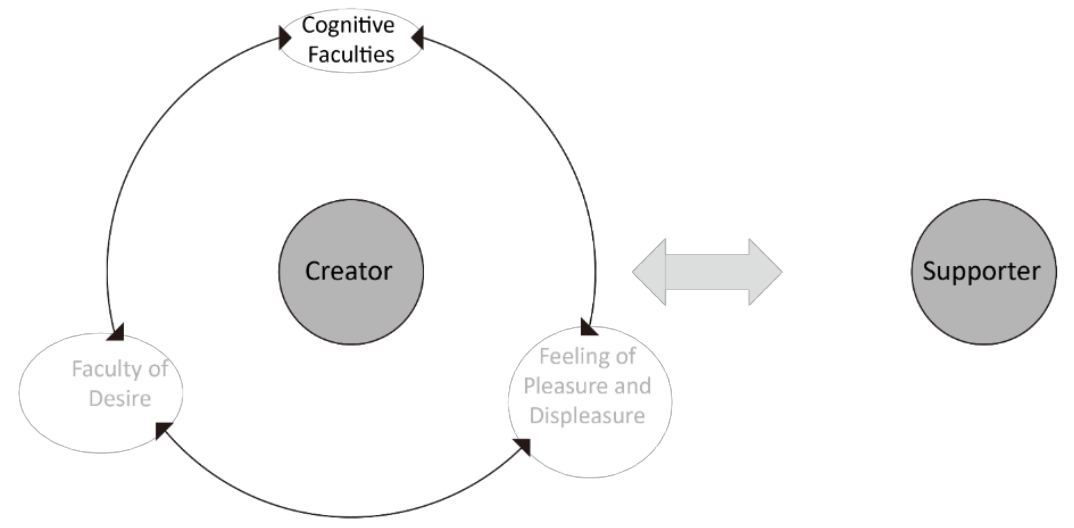

Figure 5 The role of designers as creators and the role of computers as supporters

\subsubsection{The second phase: algorithm-aided parametric design}

Parametric design is "a process of choosing appropriate parameters for a design problem and setting up the model definition that then can be used to explore the solution space" (Gane, 2004, p. 37). In modern society, which is becoming increasingly complex, designers need a lot of information to solve problems. The main function of parametric design is to process optimised designs in a short period of time through a large and complex calculation process that makes use of algorithms. This allows designers to design more diverse forms under the same conditions by utilising the calculated information. On the algorithm, designers can create and modify the shape by combining various components and adjusting the parameters. Here, the designers take the various conditions into account to find a more appropriate form. Oxman (2017) said, "In the context of algorithmic design, being reflective relates to the designer's ability to understand and control the computational and scripting tools" (p. 10). As a result, parametric design provides logical information to designers and it helps them to clearly set and achieve their design goals. In other words, the designers adjust the parameters to design the shape that fits the purpose, and the computer calculates it in real time and shows it to the designers. Computers help designers make better use of the faculty of desire to solve the problem by designing artefacts. As can be seen in Figure 6 , the role of designers as utilisers and the role of computers as providers can be defined in relation to each other.
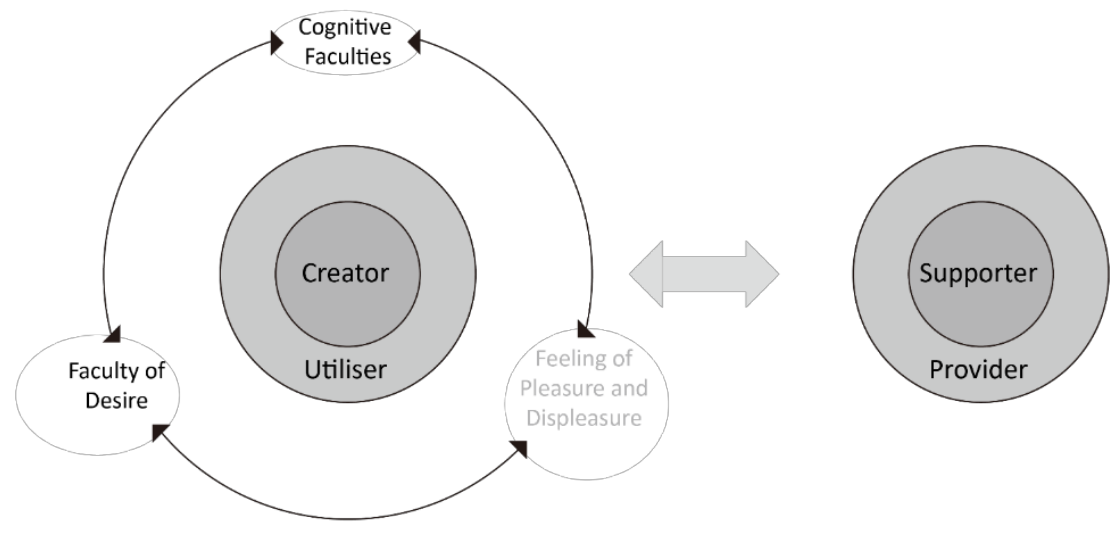

Figure 6 The role of designers as utilisers and the role of computers as providers 


\subsubsection{The third phase: artificial intelligence-aided generative design}

Generative design is typically described as a rapidly repeating process through computers to explore as many design solutions as possible. In the case of the Autodesk Dreamcatcher, a generative design software, designers can enter conditions into the form of a given prototype to produce many variations of a design proposal. Designers can arrange proposals in order based on their preferences, or they can enter additional settings to allow the computers to generate other forms. As a result, the computers propose many forms to designers, and the designers can then choose among the proposals, making it more likely that they will provide satisfactory designs to customers. At this point, computers help designers make better use of the faculty, feeling of pleasure and displeasure, to make satisfactory design outcomes. Although artificial intelligence technologies are not yet widely available, we can imagine situations in which they will be used for design work. For example, in a scene from the movie Iron Man (2008), Jarvis, an artificial intelligence secretary, asks Tony Stark about the material and colour that will be applied to Iron Man suit, and he proposes a threedimensional rendering. Tony Stark replies, 'I like it. Fabricate it. Paint it'. In the same vein, as an iterative process, designers can train artificial intelligence a kind of style by entering the selected result among the proposals back into the tool. In other words, "designers will train their artificial intelligence tools to solve design problems by creating models based on their preferences" (Girling, 2017). As can be seen in Figure 7, the role of designers as judges and the role of computers as proposers can be defined in relation to each other.

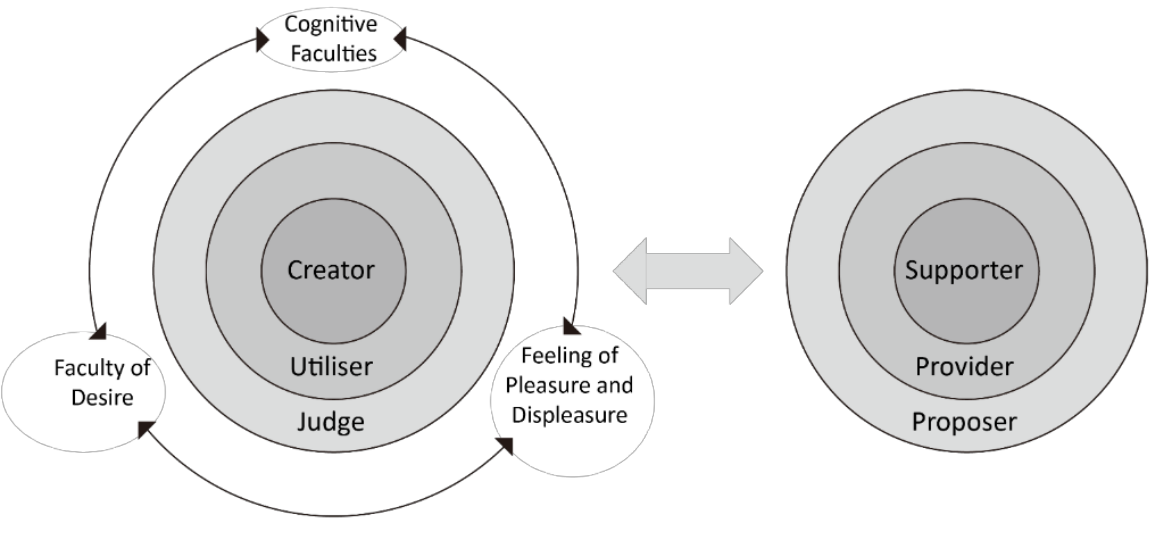

Figure 7 The role of designers as judges and the role of computers as proposers

\section{Conclusion}

The development of computer technology and the emergence of artificial intelligence raise serious questions about the faculties and roles of humans. The same is true for the faculties and roles of designers who use computers as their main tool. In this paper, the inherent faculties of the human mind, revealed through the Kantian approach, were applied to designers. According to this, it was explained how designers use their own faculties in the world of human artefacts. The coevolutionary relationship between computers, as evolving tools, and designers was analysed by establishing roles in mutual relations at each phase. The roles of designers defined in this paper are not newly emerging roles, but rather, the roles, derived from the inherent faculties of the designers, are redefined in relation to computers as tools. Tools help designers to use their faculties, and the evolution of tools lead designers to newly regulated roles. Through such roles, designers become better able to use their own faculties.

This study is the starting point of a discussion about designers' roles that co-evolve with tools. For further research, we will analyse the collaborative relationship between designers and tools using actual artificial intelligence design software which is going to be commercialized soon, and based on this, we will develop a framework for changes in the future design process that reflects the roles of designers co-evolving with tools. 


\section{References}

Bergson, H. (1998). Creative Evolution (A. Mitchell, Trans.). Mineola, New York, USA: Dover Publications.

Bush, V. (Jul 1945). As We May Think. The Atlantic. Retrieved from https://www.theatlantic.com/magazine/archive/1945/07/as-we-may-think/303881/

Cross, N. (2001a). Designerly Ways of Knowing: Design Discipline Versus Design Science. Design Issues, 17(3), 49-55. doi:10.1162/074793601750357196

Cross, N. (2001b). Can a Machine Design? Design Issues, 17(4), 44-50. doi:10.1162/07479360152681083

Cross, N. (2008). Engineering Design Methods: Strategies for Product Design (3rd ed.). Wiley

Engelbart, D. C. (1962). Augmenting Human Intellect: A Conceptual Framework. AFOSR-32323, Stanford Research Institute, Menlo Park, California.

Favreau, J. (Director). (2008). Iron Man [Motion Picture]. United States: Marvel Studios.

Gane, V. (2004). Parametric Design: A Paradigm Shift? Master's Thesis, MIT, Cambridge.

Girling, R. (2 Jun 2017). Al and the Future of Design: What will the designer of 2025 look like? Artefact. Retrieved from https://www.artefactgroup.com/articles/ai_design_2025/

Heidegger, M. (1996). Being and Time (J. Stambaugh, Trans.). State University of New York Press.

Kant, I. (1979). The Conflict of the Faculties (M. Gregor, Trans.). Abaris Books.

Kant, I. (1998). Groundwork of the Metaphysics of Morals (M. Gregor, Trans.). Cambridge University Press.

Kant, I. (2006). Anthropology from a Pragmatic Point of View (R. Louden, Trans.). Cambridge University Press.

Kant, I. (2007). Critique of Judgement (J. Meredith, Trans.). Oxford University Press.

Kowalski, J. (5 Jan 2016). CAD Is a Lie: Generative Design to the Rescue. Redshift. Retrieved from https://www.autodesk.com/redshift/generative-design/

Lawrence, A. (21 Dec 2015). The Good, The Bad, The Ugly: Konstantin Grcic's chair_ONE. Disegno. Retrieved from https://www.disegnodaily.com/article/konstantin-grcic-chair_one

Licklider, J. C. R. (1960). Man-Computer Symbiosis. IRE Transactions on Human Factors in Electronics, HFE-1, 411.

Oxman, R. (2017). Thinking difference: Theories and models of parametric design thinking. Design Studies, 52, 4-39. doi:10.1016/j.destud.2017.06.001

Vidal, R., Mulet, E. (2006). Thinking about computer systems to support design synthesis. Communications of the ACM, 49, 100-104. doi:10.1145/1121949.1121955

About the Authors:

Jeong-Sub Lim is a graduate student (master's degree) of design department at Seoul National University. From the perspective of human-centered design, his research focuses on the areas of the design thinking process and the future role of designers.

Eui-Chul Jung is an associate professor of design department at Seoul National University. He teaches and writes in the areas of interactive product and UX design, information visualization, and human-centered design and methodology. 